\title{
Alfredo Jaar: "Soy un arquitecto que hace arte"
}

Adriana Valdés Profesora, Universidad de Chile

La obra de Alfredo Jaar se sitúa en el límite entre la arquitectura y el arte. Salas de exposición en el paisaje, museos temporales o instalaciones en la ciudad; todas tienen el denominador común de traer a presencia problemas sociales que no se ven a simple vista. Son cuestionamientos acerca de lo que no somos capaces de percibir o sentir.
The work of Alfredo Jaar is situated on the limit between architecture and art. Exposition halls in the landscape, temporary museums or city installations; all have the common denominator of bringing to light social problems that are not seen on the surface. They are investigations questioning that which we are incapable of perceiving or feeling.
Un tema tan amplio como el de las relaciones entre la arquitectura y las artes visuales puede abordarse de muchas maneras. Una muy concreta es referirse a la práctica de Alfredo Jaar, el artista chileno contemporáneo más reconocido a nivel internacional. Su obra no tiene fronteras en lo geográfico y tampoco en cuanto a las disciplinas; las fronteras entre arte, arquitectura y cine, por ejemplo, se vuelven sumamente fluidas. Se mueve entre unas y otras según las necesidades del problema que cada lugar y cada obra le plantea. "No sé si será por mi formación, pero yo he sido incapaz de crear una sola obra de arte que no sea en respuesta $a$ un hecho real. No lo sé hacer. No soy artista de taller, soy artista de proyectos".

La formación a que se refiere tuvo lugar en Chile durante la dictadura ${ }^{1}$. Sus estudios fueron de arquitectura y cine, no de arte. Su carrera se desarrolló a partir de 1982 en Nueva York (donde comenzó trabajando en la oficina de arquitectos site) y lo ha llevado a exponer y a crear obras en más de veinticinco ciudades en América, África, Asia y Europa.

En el lenguaje con que describe su propia actividad se aprecia la influencia de su formación de arquitecto. Los hechos reales se plantean como problemas y la obra es el resultado de una programación de actividades, que incluyen la investigación acerca del lugar y todas las etapas de producción y montaje. Cada problema lleva a la exploración de medios y formatos distintos, que tienen menos que ver con las exigencias de los formalismos del arte y más con las características del lugar en que la obra se origina.

A continuación se habla acerca de algunas de sus obras, las más relacionadas con los temas que se plantean espontáneamente cuando se piensa en arte y arquitectura: los museos, el arte en las ciudades y la arquitectura dentro de las obras mismas, es decir, en las instalaciones. MusEos / Jaar ha señalado en entrevistas que "hay problemas en la arquitectura de museos. Hay arquitectos que se creen artistas y crean espacios arquitectónicos imposibles para el arte, como Frank Gehry. Crean verdaderas esculturas a sí mismos. Hay otros, como Renzo Piano, que crean espacios respetuosos, limpios, silenciosos, donde el artista puede trabajar"2.

Más allá de estas opiniones, Jaar ha creado obras que implican una reflexión sobre los espacios de exhibición del arte, sobre la necesidad del arte y su interacción con la vida de los lugares. Tres sirven de ejemplo aquí y se presentan en orden cronológico.

La primera, de 1996: Camera lucida, en Catia, un barrio pobre de Caracas. Se trataba de inaugurar un museo rechazado por los habitantes del barrio, quienes habían pedido, en su lugar, un recinto deportivo. El artista invitó a los vecinos, distribuyó máquinas fotográficas desechables y películas y a cambio pidió sólo una foto del barrio, sacada por cada uno. Cuando las recibió, hizo un montaje notable en el nuevo museo, jugando con tamaños y formatos. Éste fue por cierto visitado por mucha gente: muchos retrataron y muchos se sintieron retratados allí. Se creó así un lazo con el museo, una manera de que fuera sentido como propio; hoy tres personas del barrio integran su directorio. Se creó también una relación con el arte, no como algo ajeno y externo, sino como algo que se produce desde la propia experiencia, que permite verla y compartirla.

La segunda obra, de 2000, Bunka no Hako-La caja de la cultura-, se hizo en Japón (Figs. 01 a 03). Los fondos del encargo, que no alcanzaban para un museo, se destinaron a la construcción de varios recintos ubicados en altura, en distintos paisajes; lugares que permitían, en un primer piso, exhibir pequeñas obras de artistas locales, además de reposar al aire libre antes de entrar. Luego, por una escalera lateral amplia, se subía a una especie de azotea, donde el majestuoso paisaje de los cerros japoneses se podía ver en $360^{\circ}$. Oponiéndose a la monumentalidad propia de los museos, a la distancia del espectador respecto de las obras (tanto física como cultural) y a la cerrazón respecto del entorno, el recorrido propuesto integraba el arte de producción local a una experiencia de reposo, contemplación y comunión con la naturaleza. Una experiencia a escala individual, o de grupos muy pequeños, con un alto grado de espiritualidad y de silencio.

Por último (y ésta es tal vez una de las imágenes más difundidas de obra de Alfredo Jaar en el mundo) Skoghall Konsthall: el museo de Skoghall, una pequeña ciudad industrial sueca, nueva y prácticamente sin espacios públicos. Se trató de un pequeño museo hecho también en 2000, enteramente de papel, con un esqueleto simple de madera (Figs. 04 a 07). El programa del artista exigió que los materiales del museo vinieran de la industria papelera que sostiene la economía del lugar; que el recinto, una vez construido, fuera sede de una exposición de trabajos de artistas jóvenes invitados; que fuera inaugurado por el alcalde con la pompa y la música propia de tales ceremonias. Debía ser abierto al público y, al tercer día, debía ser consumido por el fuego, con todos los cuidados del caso para evitar daños o desgracias. A diferencia de la obra hecha en Japón, cuyo impacto dependería del uso que le diera cada uno de los visitantes, Skoghall Konsthall estaba destinada a señalar al colectivo de los habitantes del lugar una necesidad de la que probablemente no estaban conscientes. Las protestas que se produjeron ante la quema del edificio, las solicitudes de mantenerlo, el carácter programadamente efímero, tenían por objeto hacer patente la necesidad de un espacio semejante y crear entre los ciudadanos las fuerzas de cooperación capaces de conseguirlo. Fue un objetivo que finalmente se cumplió, y el museo definitivo se construirá en la ciudad.

Estas tres obras de Alfredo Jaar (y otras que podrían comentarse) dan que pensar acerca de la relación entre la arquitectura, el arte y los museos. Hay en ellas una noción de exhibir y pensar un arte cercano, a escala humana, ajeno a las multitudes del turismo, al star system, 
1 El período de dictadura en Chile tiene lugar entre 1973 y 1990 durante el gobierno de la Junta

Militar presidida por el general Augusto Pinochet Ugarte (N. del Ed.).

2 Véase "Alfredo Jaar, conversaciones en Chile 2005" en JAAR, SCL 2006. En este libro se presenta una completa información gráfica sobre la obra del Accatino, Pablo Chiuminatto, Bruno artista hasta ese año. Su título cor- Cuneo, Ana María Risco y Rodrigo responde a la importante exposición Zúñiga. Salvo cuando se indica, las presentada en la Sala de Arte de la citas textuales del artista provienen Fundación Telefónica Chile. Incluye del texto de las conversaciones. Más información e imágenes de sus obras en www.alfredojaar.net.
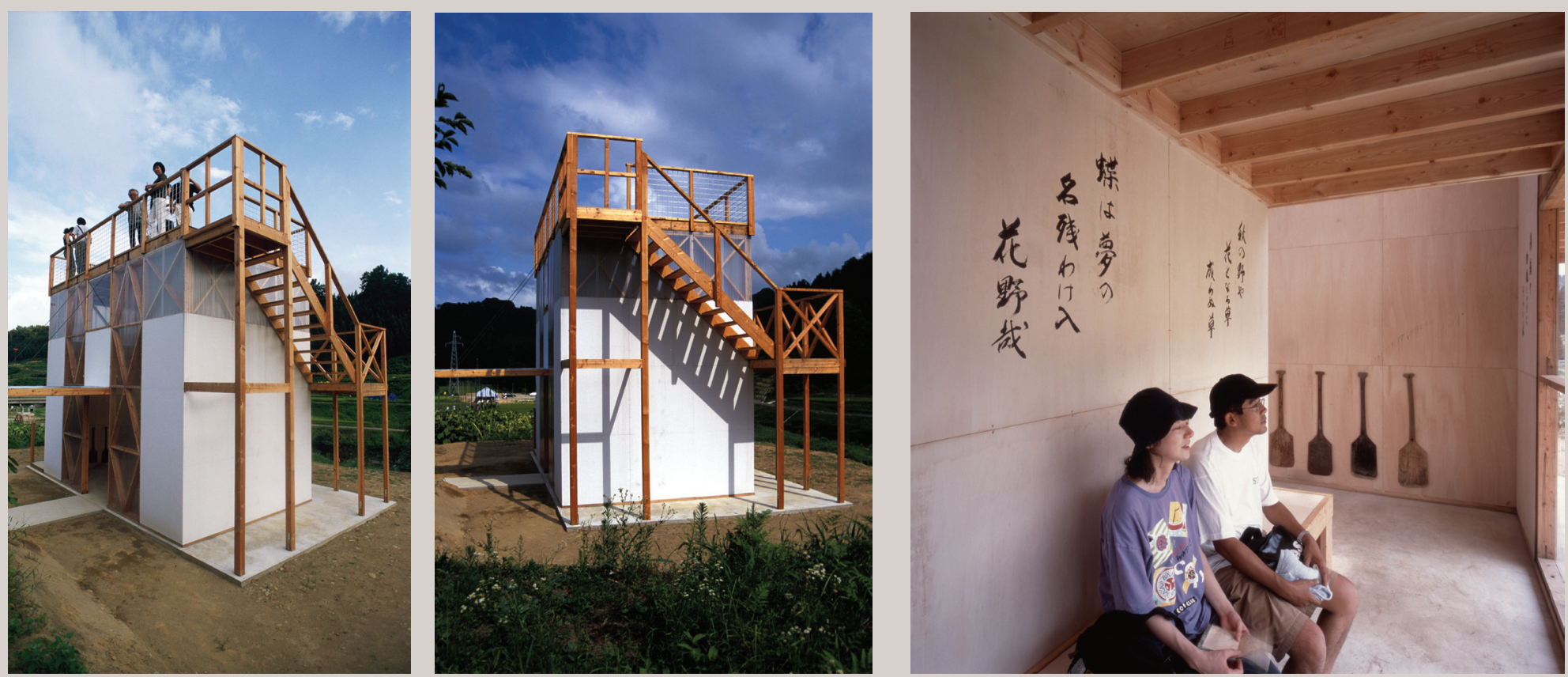

01 a 03 Bunka no Hako, Japón, 2000
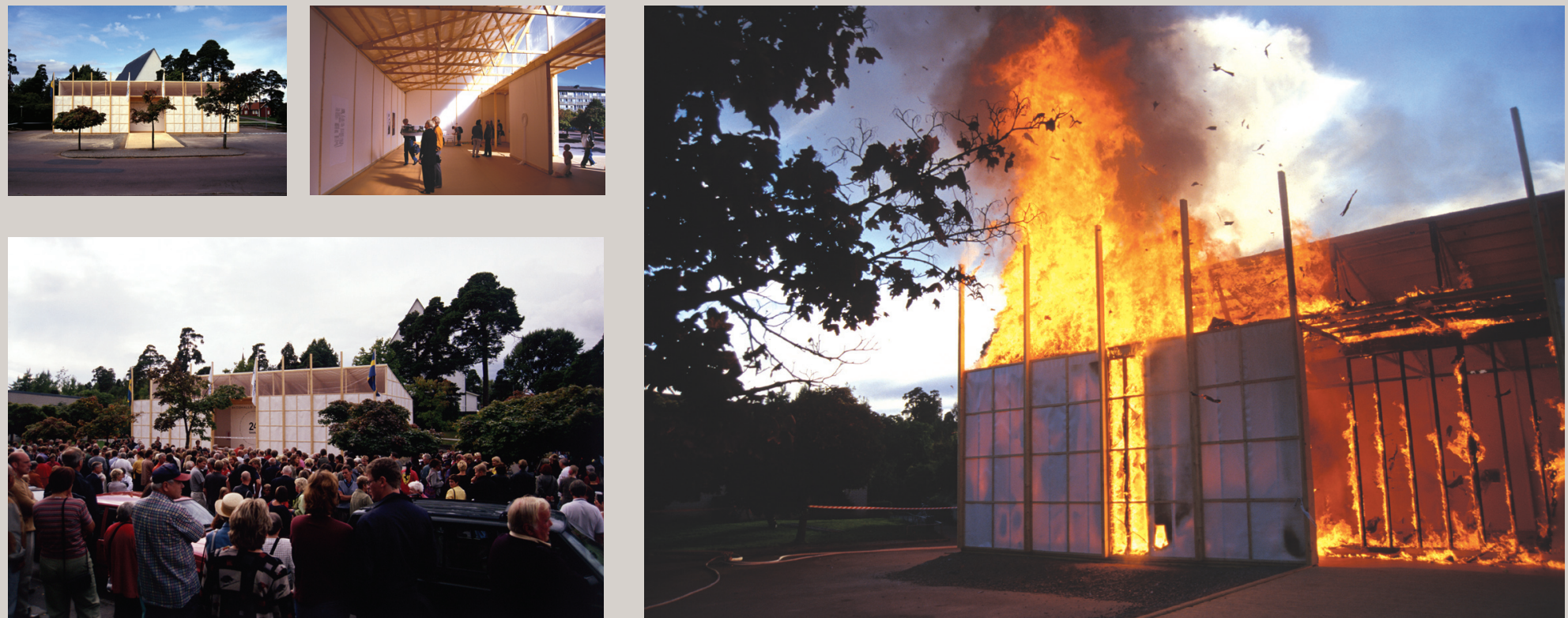

04 a 07 Skoghall Konsthall, Skoghall, Suecia, 2000. 


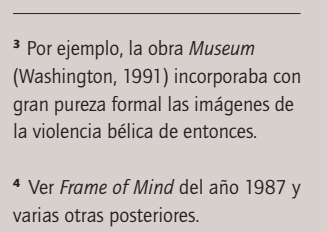

5 Ver "Conversaciones en Chile 2005",

Op. cit.

6 Otro ejemplo notable, más reciente, es Requiem for Leipzig, 2005. varias otras posteriores.
7 Ver el capítulo de Jacques Rancière, "El teatro de las imágenes" del libro de Alfredo Jaar, La política del libro de Alfredo Jaar, La política de las imágenes, 2008. Éste incluye ensayos de Georges Didi-Huberman, Jacques Rancière, Griselda Pollock, Nicole Schweizer y Adriana Valdés.
Los primeros cuatro se publicaron poŕs glés en el catálogo de la exposición de Alfredo Jaar La politique des images, bajo la dirección de Nicole Schweizer, en 2007.
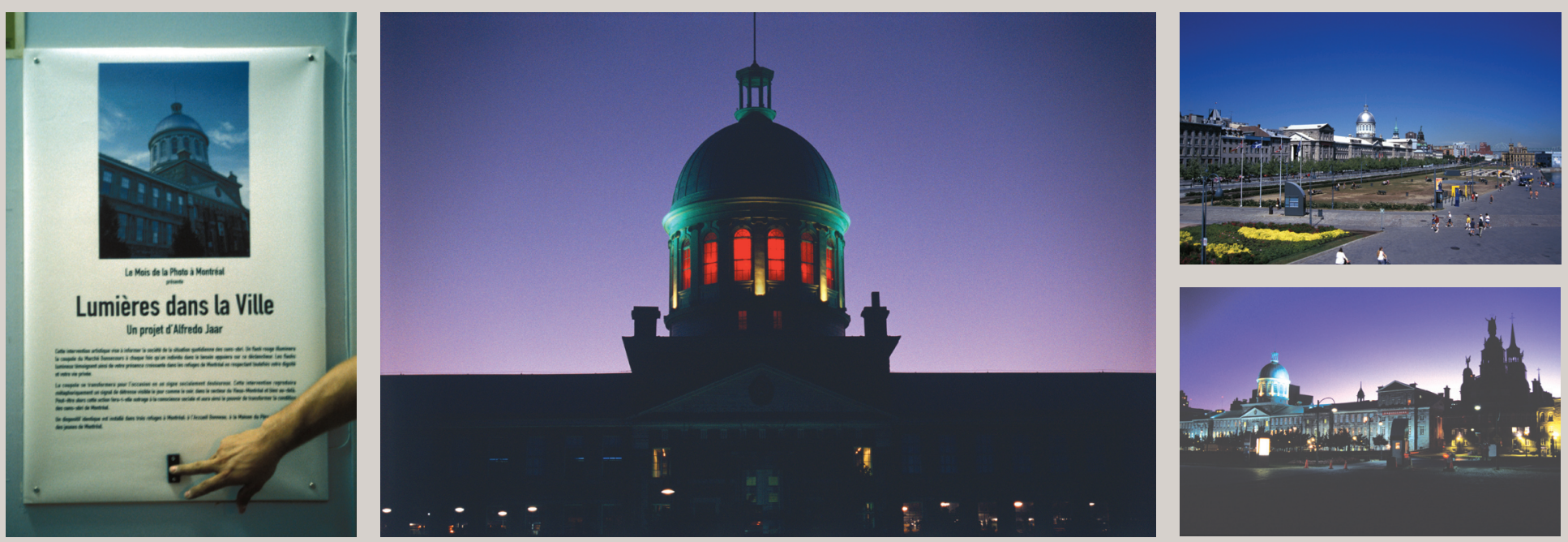

08 a 11 Lights in the city, Montreal, Canadá, 1999.

al comercio; un arte que hace entrar lo que las galerías y los museos suelen excluir ${ }^{3}$. Un arte que se descuadra y se desmarca de las expectativas visuales del público en busca de una renovación de la mirada y de una visibilización de lo que, en las coordenadas actuales de lo visible, permanece oculto a los ojos. ${ }^{4}$

EL ARTE Y LAS CIUDADES: INTERVENCIONES / Jaar dedica un tercio de su tiempo a la enseñanza en seminarios muy concentrados en diversas partes del mundo, otro tercio a las obras destinadas a espacios de arte y un último tercio a las intervenciones públicas ${ }^{5}$. La lista de ciudades visitadas es larga. Basta Lights in the city (Luces en la ciudad), de 1999 en Montreal, para mostrar cómo un elemento que forma parte de la imagen y de la identidad pública de la ciudad es intervenido por el artista para transformarlo, por un tiempo, en una señal simbólica de algo que allí sucede (Figs. 08 a 11). Sin embargo es un elemento que no está ni integrado ni asumido, ya que en cierto sentido perturba la identidad establecida de la ciudad. ${ }^{6}$

En el caso de Montreal, el problema abordado por el artista fue el de "las personas en situación de calle", como se dice hoy en Chile. De las posibilidades que le daba el encargo escogió trabajar con la cúpula del edificio del Mercado Bonsecours, de gran carga histórica y visible desde gran parte de la ciudad. Creó en los albergues nocturnos un sistema que permitía a los hospedados, al llegar, leer una pequeña información acerca del proyecto y apretar un botón que iluminaba la cúpula desde dentro, con una luz roja e impactante. Logró así un doble objetivo: hacer patente y visible, sucesivamente, el abandono de cada una de las personas y además proteger la intimidad de cada una, sin añadir a sus penurias la estigmatización social. El efecto fue, como se aprecia en los registros (Figs. 10 y 11), de una rara belleza, de un suspenso inquietante. El ritmo de las luces dependía de lo que iba sucediendo en cada uno de los albergues; el discurso hipócrita y sensiblero que suele acompañar -y neutralizar- las referencias a estas situaciones en los medios de comunicación se reemplazó por el silencio, la sorpresa, la inquietud y finalmente la emoción sobre la que Jaar suele trabajar como un elemento político más ${ }^{7}$. Es decir, un elemento capaz de hacer que se tome en cuenta algo que no estaba, hasta ahora, incluido en las coordenadas de lo visible.

Otra intervención muy distinta, mucho más reciente y menos conocida está en proceso de concretarse. Se trata de un proyecto de renovación en la ciudad de Preston en Lancashire, Reino Unido, al cual se ha incorporado Alfredo Jaar junto al artista y curador Charles Quick, residente en la ciudad. En marzo de 2007, ambos hicieron una presentación pública acerca de lo que puede hacer el arte en un proyecto de renovación urbana, en el marco de una iniciativa que busca incorporar al arte no como un ornamento o una decoración para un espacio ya creado por los arquitectos, sino como una dimensión presente desde el origen del proyecto. En cuanto al tema que nos ocupa, arte y arquitectura, son reveladoras las reflexiones de Jaar en esa intervención. En sus ejemplos citó una obra de Vito Acconci: una isla artificial sobre el río Mur en Graz, creada en 2003 como un encargo de la ciudad. "iArte o arquitectura: acaso importa?" se preguntó. Y la misma pregunta se hizo sobre un edificio que consideró admirable: The Laban Building en las afueras de Londres, de los arquitectos suizos Herzog y De Meuron, quienes trabajaron junto al artista Michael Craig-Martin. El arte, sostuvo, puede incorporarse a un entorno ya hecho, como el trabajo de Anish Kapoor Cloud Gate en Chicago, y llegar a ser del lugar. Si los arquitectos son suficientemente creativos, si realmente logran transformar la ciudad, el arte puede estar en el espacio mismo, sin necesidad de otras obras. En resumen el arte puede ser nada, y ser todo. La nada del arte puede ser todo en la medida en que esté presente en la concepción del proyecto. Como se ve en estas opiniones, las fronteras entre arte y arquitectura se vuelven tan fluidas que pueden llegar a desaparecer. "Las obras aisladas", dijo entonces Jaar, "por cierto pueden estar, si la arquitectura las necesita. Pero es posible que no las necesite". Es posible entonces (y es tal vez la apuesta de este proyecto) crear una arquitectura que produzca por sí misma los efectos que se le pueden pedir al arte. (Jaar y Quick, 2007)

ARQUITECTURA PARA LAS IMÁGENES / En muchas de las instalaciones de 
${ }^{8}$ Georges Didi-Huberman, "La emoción no dice 'yo'". Op. cit., p. 54.

9 Ha sido expuesto en: Houston, EE.UU.; Brighton y Londres, Reino Unido y Lausanne, Suiza.
10 Jacques Rancière, "El teatro de

las imágenes". Op. cit,. p.87.

" Griselda Pollock, "Sin olvidar África", Op. cit., p. 93.

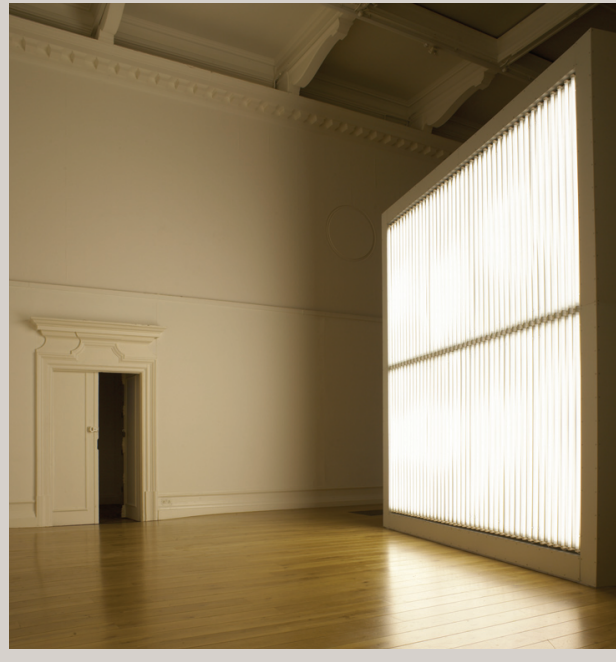

12 a 14 The sound of silence, 2006
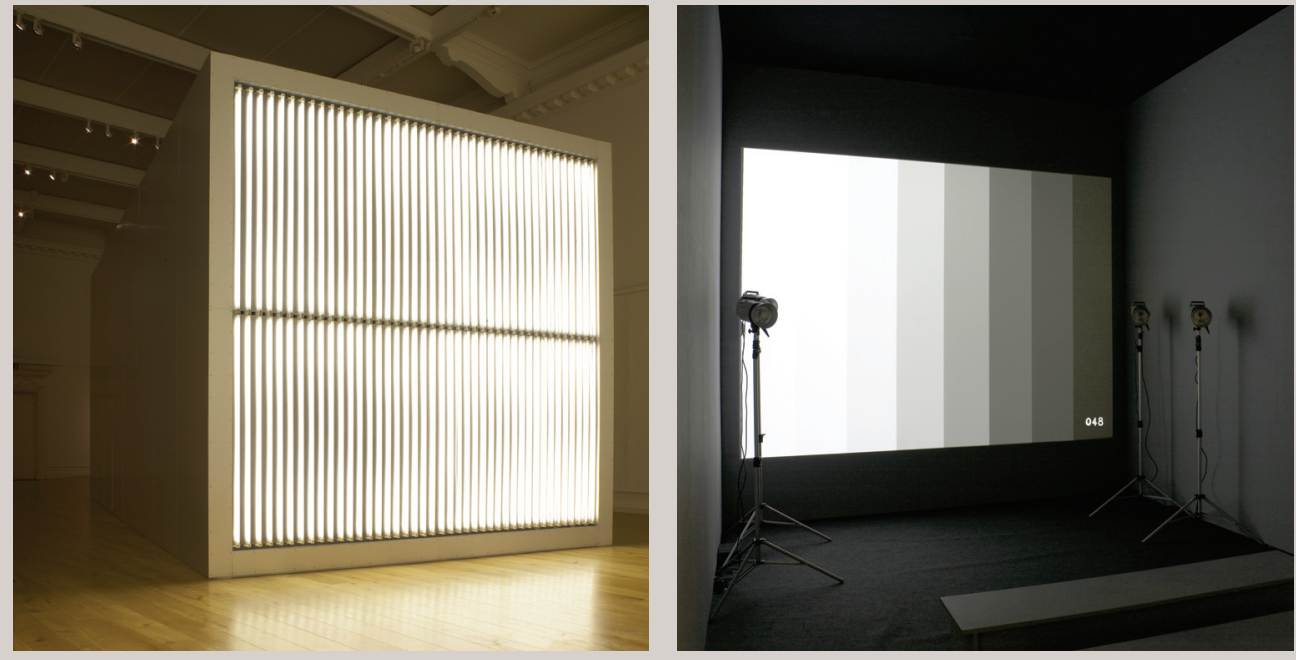

Alfredo Jaar, la arquitectura está muy presente: se configuran espacios, recorridos y tiempos, se maneja la presencia de la luz y de los reflejos, se construye un recinto hecho para sorprender y modificar la percepción de las imágenes presentadas. Todo esto se hace necesario para el artista debido a cómo percibe la condición de las imágenes en la cultura actual; no la de cualquier imagen, sino sobre todo las de las imágenes del sufrimiento extremo, pan de cada día en diarios y noticiarios de televisión, sobre las que los ojos se deslizan con rapidez y notoria indiferencia. Ante esto, dice el artista, "me ha parecido necesario crear una puesta en escena para mis imágenes, un entorno dentro del cual puedan llegar a tener sentido y afectar al público (...) Me parece que sin este entorno protector, mis imágenes no sobrevivirían. Pienso que es indispensable reducir la velocidad, contextualizar y enmarcar cada imagen adecuadamente a fin de que adquiera sentido y no pueda ser dejada de lado." (Jaar, 1999)

La arquitectura, entonces, es en las obras un elemento de montaje y de puesta en escena de las imágenes. "No sólo el encuadre es político (...) Cada elección formal (...) repercute (...) en la relación con el acontecimiento y la historia" . Las elecciones implícitas son estéticas, pero también más que eso: Jaar suele citar en sus entrevistas una frase de Jean-Luc Godard: "puede que haya que elegir entre la ética y la estética, pero lo cierto es que si elegimos una de ellas, nos hallaremos al final del camino con la otra".

Los ejemplos son muchos en la obra de este artista. Por razones de espacio nos limitaremos a un trabajo reciente, The sound of silence, de $2006^{9}$ (Figs. 12 a 14). Construye allí un "dispositivo espacio-temporal de visión"10, un espacio cerrado, al que sólo se puede entrar, como en el teatro, al comienzo de la función. Hay que seguir durante ocho minutos un desarrollo temporal, con pocas palabras que van apareciendo, en silencio, sobre una pantalla negra, y en las que se repite "Kevin". El espectador va sabiendo que se trata del fotógrafo Kevin Carter, quien obtuvo el Premio Pulitzer por la imagen de una niña africana desnuda y famélica, sobre la que se ciernen las alas de un buitre. Carter poco después se suicidó. La foto misma sólo se ve por el tiempo que dura un flash y una vez que el espectador ha reducido su velocidad, ha conocido la historia en frases lacónicas y cargadas: se espera, entonces, que esa breve visión instantánea sea capaz de restituir a la imagen su carácter de shock a la vez estético y ético. La historia de esa niña no existe, nadie sabe qué fue de ella. La de la imagen sí se conoce, su tránsito por todas las portadas del mundo, su transformación en ícono mediático, su archivo entre las posesiones de Bill Gates. Una autora habla, en el intento de esta obra, de coreografía arquitectónica y de durée cinematográfica ${ }^{11}$ : resistir la trágica banalización de las imágenes del sufrimiento, la paradoja de una comunicación que adormece y evita cualquier emoción política, cualquier práctica de disenso o de resistencia.

Es un intento que se ha hecho una y otra vez, con distintos medios y formatos, en la trayectoria artística de Alfredo Jaar, un arquitecto que hace arte, en sus propias palabras. Cabe pensar que su obra, al menos en parte, se diferencia tanto de la de sus contemporáneos en Chile por su capacidad de pensar el arte de una manera más amplia y generosa, más interdisciplinaria. La arquitectura y el cine (ahora último, la música también) están presentes en las obras desde el momento mismo en que comienza a pensar en ellas y contribuyen poderosamente a configurar su práctica y su mirada. ARe

\section{Bibliografía}

AA, VV. Jaar SCL 2006. Ediciones Actar, Barcelona, 2006. / Jaar, Alfredo. “Blowup”. ARQ № 44, Cine y fotografía. Ediciones ARQ, Santiago, abril de 2000. / Jaar, Alfredo. It is difficult. Ten years. Ediciones Actar, Barcelona, 1998. / Jaar, Alfredo. La política de las imágenes. Ediciones Metales Pesados, Santiago, 2008. / Jaar, Alfredo. La politique des images, Catálogo exposición Musée Cantonal del Beaux-Arts, Lausanne. Éditions JRP/Ringier, Zurich, 2007. / Jaar, Alfredo y Charles Quick. Extracts from Presentation. University of Central Lancashire, 27 de marzo de 2007. http://www.youtube.com/watch?v=R_uV4YDbozQ. / Ninacs, Anne Marie. Le souci du document, Le mois de la photo a Montréal, 1999. Editorial Vox, Montreal, 1999. 